\title{
Endothelial nitric oxide synthase gene polymorphisms and cardiovascular damage in hypertensive subjects: an Italian case-control study
}

\author{
Daniela Colomba1 ${ }^{1}$ Giovanni Duro ${ }^{2}$, Salvatore Corrao ${ }^{1}$, Christiano Argano ${ }^{1}$, \\ Tiziana Di Chiara1, Domenico Nuzzo ${ }^{2}$, Federica Pizzo ${ }^{2}$, Gaspare Parrinello ${ }^{1}$, \\ Rosario Scaglione*1 and Giuseppe Licata ${ }^{1}$
}

Address: ${ }^{1}$ Department of Internal Medicine, University of Palermo, Italy and ${ }^{2}$ Institute of Biomedicine and Molecular Immunology CNR, Palermo, Italy

Email: Daniela Colomba - colomda@yahoo.it; Giovanni Duro - duro@ibis.pa.cnr.it; Salvatore Corrao - s.corrao@tiscali.it; Christiano Argano - chargano@yahoo.it; Tiziana Di Chiara - tizianadc@libero.it; Domenico Nuzzo - nuzzo@ibim.cnr.it; Federica Pizzo - pizzo@ibim.cnr.it; Gaspare Parrinello - dibimis@unipa.it; Rosario Scaglione* - rosarioscaglione@yahoo.it; Giuseppe Licata - dibimis@unipa.it

* Corresponding author

Published: 29 May 2008

Immunity \& Ageing 2008, 5:4 doi:10.1 I86/1742-4933-5-4

This article is available from: http://www.immunityageing.com/content/5/I/4

(c) 2008 Colomba et al; licensee BioMed Central Ltd.

This is an Open Access article distributed under the terms of the Creative Commons Attribution License (http://creativecommons.org/licenses/by/2.0), which permits unrestricted use, distribution, and reproduction in any medium, provided the original work is properly cited.
Received: 26 March 2008

Accepted: 29 May 2008

\begin{abstract}
Background: Nitric oxide (NO) synthesized by endothelial nitric oxide synthase (eNOS) plays an important role in regulation of endothelial function and in the control of blood pressure. However, the results from some studies on the association between three clinically relevant eNOS gene polymorphisms (G894T, T786C and intron 4b/a) and essential hypertension are unclear. We designed a case-control study to evaluate the influence of eNOS polymorphisms on target organ damage in 127 hypertensives and 67 normotensives. Clinical evaluation, biochemical parameters, Urinary Albumin Excretion (UAE) and echocardiogram were performed to characterize target organ damage. eNOS polymorphism were recognized by PCR method.
\end{abstract}

Results: The distribution of eNOS genotypes was similar in hypertensives and normotensives but $4 \mathrm{aa}$ was present in the $2.5 \%$ of hypertensives and completely absent in normotensives. Subjects with 4bb, G894T, and T786C genotypes showed an increased prevalence of target organ damage. Moreover prevalence of G894T and introne 4 variants was significantly higher in hypertensives than in normotensives both with cardiovascular damage. Logistic regression analysis didn't show any association between eNOS polymorphisms, Body Mass Index (BMI), hypertension, gender and cardiovascular damage. Only the age (OR I.II; IC 95\% I.06-I.I8) was predictive of cardiovascular damage in our population.

Conclusion: Our results seem to indicate a lack of association with eNOS variants and cardiovascular damage onset. 


\section{Background}

Hypertension is a multifactorial disease involving both environmental and genetic components. Clinical and experimental studies suggest that an alteration in nitric oxide (NO) metabolism may be a contributing factor in the pathogenesis of hypertension. Thus, abnormalities in the activity of the enzyme endothelial NO synthase (eNOS) that synthesizes NO in endothelial cells may lead to NO deficiency with severe consequences. In fact, NO plays a pivotal role in the preservation of the endothelium homeostasis, regulation of vasomotor tone and control of blood pressure [1]

The gene encoding eNOS is located on chromosome 7 (7q35-q36) and contains 26 exons with an entire length of $21 \mathrm{~kb}$. Disruption of eNOS gene leads to hypertension in mice [2] and inhibition of eNOS elevates blood pressure in healthy humans [3]. Furthermore, NO production is diminished in patients with essential hypertension (EH), under basal conditions [4]. On this important evidence the eNOS gene has been investigated as a putative candidate gene for EH. G894T, T786C and intron 4 (4b/ a) are the most clinically relevant polymorphisms in the eNOS gene that have been described. However, the results of most association studies were inconsistent among different ethnicities and even among different populations from the same ethnicity [5-7].

The single nucleotide polymorphism (SNP), G894T within exon 7 , resulting in a replacement of glutamic acid by aspartic acid at codon 298 (Glu298Asp), is the most highlighted variant whose association with hypertension is still controversial. In particular, the G894T was found to be associated with increased risk of hypertension in Caucasian [8] and Japanese [9], but in another two studies it was not (neither in Caucasian nor in Japanese) $[10,11]$. Recently, a functional 27-bp variable number of tandem repeats (VNTR) in intron 4 (intron $4 \mathrm{~b} / \mathrm{a}$ ) of eNOS gene has been reported to coordinate with another SNP at the promoter region (T786C). It regulates transcription efficiency in a haplotype-specific way which is modifiable by cigarette smoking [12]. Although no association has been reported between intron4b/a, T-786C and hypertension, most association studies did not examine the combining effect of these two polymorphisms on the development of hypertension $[9,13,14]$. Nonetheless, it is generally accepted that these variants can modify the NO production and may predispose non only to hypertension [5] but also to ischemic heart disease [15] or renal damage [16].

The aim of the present study was to investigate the relationship between eNOS polymorphisms, G894T, T786C and intron $4 \mathrm{~b} / \mathrm{a}$ and cardiovascular damage in hypertensive patients. The main goal of the study was to evaluate if
eNOS polymorphisms might be associated to cardiovascular damage in these subjects.

\section{Methods}

We enrolled 127 subjects aged from 40 to 55 years, screened at the Department of Internal Medicine, University of Palermo (Italy). Subjects were considered to be hypertensive if their systolic/diastolic blood pressure was $\geq 140 / 90 \mathrm{~mm} \mathrm{Hg}$, confirmed in three following measurements; or $\geq 130 / 85 \mathrm{~mm} \mathrm{Hg}$ if diabetic; or if the subjects were on hypertensive therapy. A mercury sphygmomanometer was used with cuff of suitable dimensions in all the obese subjects. The degree of obesity was assessed through the Body Mass Index (BMI) and the distribution of the fat, central or peripheral, through the analysis of the waist/hip ratio (WHR) [17]. Family history for early cardiovascular events were analyzed as previously reported [18].

We also recruited 67 normotensive controls aged 40 to 55 years. Written informed consent was obtained from all the subjects enrolled in this study and this study was approved by Ethic Committee of our Institution.

Exclusion criteria included secondary hypertension, endocrinal disease, cardiovascular diseases (defined as myocardial infarction and recent stroke within previous 6 months, heart failure) severe chronic renal failure, alcoholism and psychiatric problems. All patients were subsequently divided into two groups according to the presence of target organ damage such as left ventricular hypertrophy, carotid atherosclerosis, microalbuminuria, retinopathy and diabetes mellitus. At the time of enrolment, Blood Urea Nitrogen (BUN), creatinine and clearance, glycaemia, electrolytes (serum sodium, potassium, chloride), were measured for each patient by routine laboratory methods. Genotyping was performed by investigators blinded to clinical status.

\section{Genotype determination}

Genomic DNA was prepared from blood leukocytes by established methods (kit Promega). The presence of the T786C and G894T eNOS polymorphisms was examined by PCR-RFLP analysis. The introne 4 polymorphism was investigated by voltage gradient gel electrophoresis (VGGE). To ensure objectivity, DNA analysis was blinded to clinical status of the patients.

A set of primers was designed to amplify a 206 bp fragment including the missense Glu298Asp variant (G894T polymorphism) [5'-CAT GAG GCT CAG CCC CAG$3^{\prime}$ (foward) and 5'-AGT CAA TCC CTT TGG TGC TCA C-3' (reverse)]. The PCR fragment digested overnight at $37^{\circ} \mathrm{C}$ with the $\mathrm{MboI}$ restriction enzyme was separated by electrophoresis on $2 \%$ agarosium gel and visualized by etidium 
Table I: Clinical and biochemical characteristics of the studied population

\begin{tabular}{|c|c|c|c|}
\hline & Normotensives & Hypertensives & $p<$ \\
\hline Patients $\left(n^{\circ}\right)$ & 67 & 127 & \\
\hline Women (\%) & 58 & 56 & \\
\hline Men (\%) & 42 & 44 & \\
\hline Age (years) & $48.5(40.0-55.0)$ & $50.0(44.0-57.0)$ & 0.002 \\
\hline Weight (Kg) & $77.4(66.0-85.0)$ & $80.0(70.0-90.5)$ & n.s. \\
\hline $\operatorname{High}(\mathrm{cm})$ & I.7 (1.6-I.7) & $1.7(1.6-1.7)$ & n.s. \\
\hline $\mathrm{BMI}\left(\mathrm{Kg} / \mathrm{m}^{2}\right)$ & $27.1(25.5-31.2)$ & $29.3(26.8-32.4)$ & n.s. \\
\hline WHR & $0.9(0.9-1.0)$ & $0.9(0.9-1.0)$ & n.s. \\
\hline $\mathrm{SBP}(\mathrm{mmHg})$ & I27.5 (| | $5.0-\mid 30.0)$ & $140.0(130.0-150.0)$ & 0.001 \\
\hline $\mathrm{DBP}(\mathrm{mmHg})$ & $80.0(70.0-85.0)$ & $90.0(80.0-95.0)$ & 0.001 \\
\hline $\mathrm{MBP}(\mathrm{mmHg})$ & $94.2(86.7-100.0)$ & $106.7(98.8-113.3)$ & 0.001 \\
\hline BUN (mg/dl) & $36.0(31.0-39.0)$ & $37.5(33.3-44.0)$ & n.s. \\
\hline Creatinine $(\mathrm{mg} / \mathrm{dl})$ & $0.8(0.7-0.9)$ & $0.8(0.7-0.9)$ & n.s. \\
\hline Clearance $(\mathrm{ml} / \mathrm{min})$ & $126.0(100.3-153.0)$ & II $2.0(88 .|-| 40.0)$ & n.s. \\
\hline $\operatorname{AER}(\mathrm{mg} / 24 \mathrm{~h})$ & $53.4(2 \mid .3-150.5)$ & $73.6(44.4-122.0)$ & 0.05 \\
\hline $\operatorname{LVM}(\mathrm{g})$ & $\mid 45.8(|| 8.2-176.8)$ & $161.1(143.4-192.0)$ & 0.007 \\
\hline $\mathrm{LVM} / \mathrm{h}^{2,7}$ & $35.7(31.7-43.0)$ & $41.4(36.0-49.5)$ & 0.004 \\
\hline Insulin $(\mu \mathrm{Ul} / \mathrm{ml})$ & $8.0(4.5-12.4)$ & $10.5(8.0-15.0)$ & n.s. \\
\hline
\end{tabular}

BMI: body mass index; WHR: waist/hip ratio; PAS: systolic artery pressure; PAD; diastolic artery pressure; PAM: media artery pressure; BUN: blood urea nitrogen; AER: albumin excretion rate; LVM: left ventricular mass; LVM/h2.7: left ventricular mass $/ h^{2}$ igh ${ }^{2.7}$.

Data are presented as median (lower-upper quartiles)

Table 2: Prevalence of the clinical characteristics and the comorbidities in hypertensives and normotensives

\begin{tabular}{llll}
\hline & & Normotensives n.67 & Hypertensives n.I27 \\
\hline Family history for early CV events (\%) & 0.0 & 8.6 & \\
Family history for not early CV events (\%) & 36.8 & 52.4 & 0.04 \\
Family history for diabetes mellitus (\%) & 13.2 & 15.2 & n.s. \\
Diabetes mellitus (\%) & 3.0 & 5.5 & n.s. \\
Retinopathy (\%) & 23.3 & 68.4 & n.s. \\
LVH (\%) & 13.9 & 28.7 & 0.001 \\
Carotid Atherosclerosis (\%) & 20.6 & 51.3 & 0.04 \\
Normal weight (\%) & 21.6 & 10.2 & 0.001 \\
Overweight (\%) & 46.0 & 43.9 & n.s. \\
Obesity (\%) & 32.4 & 45.9 & n.s. \\
Central obesity (\%) & 71.4 & 80.0 & n.s. \\
\hline
\end{tabular}

$\mathrm{CV}=$ cardiovascular; LVH: left ventricular mass.

bromide staining. In the presence of a $T$ nucleotide at position 894 corresponding to Asp 298, the 206 bp PCR product was cleaved into two fragments of 119 and $87 \mathrm{bp}$; whereas the presence of a $\mathrm{G}$ removed the restriction site recovering a single fragment of $206 \mathrm{bp}$. The T-C transition at position 786 in the $5^{\prime}$ flanking region of eNOS gene was investigated by PCR using 5'-ATG CTC CCA CCA GGG CAT CA-3' (foward) and 5'-GTC CTT GAG TCT GAC ATT AGG G-3' (reverse), as primers. The PCR fragment (236 bp long) was digested with the NgOAIV restriction enzyme overnight at $37^{\circ} \mathrm{C}$. The wild type (786T) has no cleavage site, whereas in the presence of $786 \mathrm{C}$ the PCR product is cleaved into two fragments of 203 and $33 \mathrm{bp}$. The 27-bp repeat polymorphism in introne 4 was investigated by 5 'AGG CCC TAT GGT AGT GCC TTT-3'(forward) and 5'TGC TCC TGC TAC TGA CAG CA-3'(reverse) as primers.
Two fragments of different length were obtained: one of $220 \mathrm{bp}$ corresponding to the allele $\mathrm{b}$ with five repetitions of 27 couples of bases and one of 193 bp (allele a) with four repetitions. Voltage gradient gel electrophoresis (VGGE) discriminate with a good resolution the two fragments on a $2 \%$ agarosium gel. In fact, 4 bb-carriers produce a visible single band of $220 \mathrm{bp}$; $4 \mathrm{ba}$ - carriers two bands, one for the allele b (220 bp) and one for the allele a (193 bp); 4aa-carriers a single band of $193 \mathrm{bp}$.

\section{Albumin Excretion Rate (AER)}

To eliminate the intra-individual day-to-day variability of AER, three consecutive $24 \mathrm{~h}$ urine collections were used. In addition, to assess the completeness of a $24 \mathrm{~h}$ urine collection, measurements of urinary rate of clearance of creatinine were evaluated. AER was measured by 
Table 3: Genotype frequency distribution of the three polymorphisms

\begin{tabular}{|c|c|c|c|c|}
\hline & & Normotensives n. 67 & Hypertensives n. I 27 & $p<$ \\
\hline \multirow[t]{4}{*}{ G894T } & GG & (19/67) 28\% & (45/I27) $35.4 \%$ & n.s. \\
\hline & GT & (4I/67) $61 \%$ & (70/I27) $55.1 \%$ & n.s. \\
\hline & TT & (7/67) II\% & (12/127) 9.5\% & n.s. \\
\hline & $\mathrm{GT}+\mathrm{TT}$ & $72 \%$ & $61.6 \%$ & n.s. \\
\hline \multirow[t]{3}{*}{ Alleles } & & $\mathrm{N}^{\circ} 134$ & $N^{\circ} 256$ & \\
\hline & G & (79/134) $59 \%$ & (160/256) 63\% & n.s. \\
\hline & $\mathrm{T}$ & (55/134) $41 \%$ & (94/256) $37 \%$ & n.s. \\
\hline
\end{tabular}

\begin{tabular}{|c|c|c|c|c|}
\hline & & Normotensives n. 38 & Hypertensives n. 107 & $p<$ \\
\hline \multirow[t]{4}{*}{ T786C } & TT & (8/38) $21 \%$ & (25/107) $23 \%$ & n.s. \\
\hline & TC & (19/38) $50 \%$ & (5I/107) 48\% & n.s. \\
\hline & $\mathrm{CC}$ & (II/38) $29 \%$ & (31/107) 29\% & n.s. \\
\hline & $\mathrm{TC}+\mathrm{CC}$ & $79 \%$ & $78 \%$ & n.s. \\
\hline \multirow[t]{3}{*}{ Alleles } & & $N^{\circ} 76$ & $N^{\circ} 214$ & \\
\hline & $\mathrm{T}$ & (35/76) $46 \%$ & (10I/2I4) 47\% & n.s. \\
\hline & $\mathrm{C}$ & $(4 I / 76) 54 \%$ & (II3/2I4) 53\% & n.s. \\
\hline
\end{tabular}

\begin{tabular}{|c|c|c|c|c|}
\hline & & Normotensives n. $3 \mathbf{I}$ & Hypertensives n. II9 & $p<$ \\
\hline \multirow[t]{4}{*}{ introne 4} & bb & $(24 / 3 I) 77 \%$ & (86/II9) $72.5 \%$ & n.s. \\
\hline & ba & $(7 / 31) 23 \%$ & (30/II9) $25 \%$ & n.s. \\
\hline & aa & $(0 / 31) 0 \%$ & $(3 / 119) 2.5 \%$ & 0.005 \\
\hline & $a b+a a$ & $23 \%$ & $27.5 \%$ & n.s. \\
\hline \multirow[t]{3}{*}{ Alleles } & & $N^{\circ} 62$ & $N^{\circ} 238$ & \\
\hline & $\mathrm{b}$ & (55/62) $89 \%$ & $(202 / 238) 85 \%$ & n.s. \\
\hline & $\mathrm{a}$ & $(7 / 62) 11 \%$ & $(36 / 238) 15 \%$ & n.s. \\
\hline
\end{tabular}

immunonephelometric assay (Bohering Institute; limit of detection, $0.1 \mathrm{mg} / \mathrm{dl}$; Inter-assay coefficient $3.5 \%$ ). Patients were defined as microalbuminuric if the level of AER was $\geq 20$ and $<300 \mathrm{mg} / 24 \mathrm{~h}$.

\section{Echocardiographic Measurements}

All patients underwent an echocardiography examination $\mathrm{M}$ and B-mode, by a computerized echocardiography (ESAOTE, Italy) for the determination of the following parameters: 1) left ventricular telediastolic internal diameter (LVIDd), 2) interventricular septum (IVSTd), and 3) posterior wall thickness (PWTd). The Penn convention was used to calculate left ventricular mass (LVM). LVM was normalized for height to the 2.7 power [19]. Accordingly, all the hypertensives with $\mathrm{LVM} / \mathrm{h}^{2.7} \geq 50 \mathrm{~g} / \mathrm{m}^{2.7}$ for men and $\geq 47 \mathrm{~g} / \mathrm{m}^{2.7}$ for women were considered to have left ventricular hypertrophy (LVH). The relative wall thickness (RWT) [(PWTd/LVIDd)x2] was also calculated. Ejection fraction from left ventricular end-diastolic and endsystolic volumes was measured from the apical four chamber view, using the ellipsoidal single-plane algorithm. Mean ejection fraction was automatically calcu- lated by the echocardiographic processing system. In our laboratory the ejection fraction calculated over five consecutive beats permitted optimal reproducibility and accuracy.

LV relaxation and filling were evaluated by pulsed-wave Doppler interrogation of the LV inflow tract from the apical four-chamber view, with the sample volume placed at the tips of the mitral valve. After a stable signal of the transmitral flow velocity was obtained, the Doppler cursor was moved toward the LV outflow tract in the apical five-chamber view for recording both mitral and aortic signals, including the closing click of the aortic valve and the opening click of the mitral valve. Doppler signals were recorded at high speed $(80-120 \mathrm{~mm} / \mathrm{s})$ with the subjects in held expiration. An average of five beats was used for analysis.

Isovolumic relaxation time (IVRT) was calculated as the time from the closure click of the aortic valve to the opening click of the mitral valve. When either the closing or opening click was not identified, the time from the end of 


\begin{tabular}{|c|c|c|c|}
\hline G894T & n. 104 & $\%$ & $p<$ \\
\hline GG & 38 & 36.5 & 0.001 \\
\hline $\mathrm{GT}+\mathrm{TT}$ & 66 & 63.5 & \\
\hline T786C & n.90 & & \\
\hline TT & 19 & 21.1 & 0.001 \\
\hline $\mathrm{TC}+\mathrm{CC}$ & 71 & 78.9 & \\
\hline Introne 4 & n.96 & & \\
\hline$b b$ & 72 & 75 & 0.001 \\
\hline$a b+a a$ & 24 & 25 & \\
\hline
\end{tabular}

the aortic flow to the onset of mitral flow from the continuous wave interrogation of the LV inflow-outflow tract was used. Peak early transmitral flow velocity (E), peak late transmitral flow velocity (A), and the deceleration time of E velocity (DTE) were measured at the tips of mitral leaflets at the maximum amplitude of $\mathrm{E}$ velocity. DTE was measured as the time from peak E velocity to the time when $\mathrm{E}$ wave descent intercepts the zero line.

\section{Carotid evaluation}

Arterial carotid wall was evaluated with high resolution Bmode ultrasonography with an ultrasound device (TOSHIBA SSA 270HG) equipped with a linear (7.5 MHz) transducer. Subjects were examined in the supine position with slight hyperextension of the neck on a longitudinal two-dimensional ultrasound image of carotid, the near and far arterial wall are displayed as two bright white lines separated by hypoechogenic space. The distance between the leading edge of the first bright line on the far wall (lume-intima interface) and the leading edge of the second bright line (media-adventitia interface) indicates the intima-media thickness of the far wall. A $1.5 \mathrm{~cm}$ segment of the common carotid artery (immediately caudal to the carotid bulb) and the proximal $1.5 \mathrm{~cm}$ segment of the internal carotid artery was considered. Within each segment, three measurements of IMT were taken ad wall thickness was not measured at the site of a discrete plaque.

\section{Statistical analysis}

Data are reported as median (lower-upper quartiles) Comparisons of continuous variables were performed with the Mann-Whitney non parametric test. Frequencies were calculated using the comparison of two independent binomial proportions according to Armitage and Berry [20]. The Fisher test was used for the analysis of tables of contingency. Moreover, to study the possible associations among the examined variables and the cardiovascular damage, a model of logistic regression was built according to Hosmer and Lemeshow [21] for the calculation of adjusted odds ratios (OR) and intervals of confidence (IC). A p values $<0.05$ was considered statistically significant.

\section{Results}

The clinical characteristics of the studied population was reported in table 1. Hypertensive and normotensive groups were homogeneous for sex, BMI, WHR. Age ( $\mathrm{p}<$ $0.002)$, systolic $(\mathrm{p}<0.001)$; diastolic $(\mathrm{p}<0.001)$; mean blood pressure $(\mathrm{p}<0.001)$, left ventricular mass indexed for height ${ }^{\wedge 2.7}(p<0.004)$ and AER $(p<0.05)$ were significantly higher in hypertensives than normotensives. The prevalence of the clinical characteristics and the comorbidities in the hypertensives and normotensives was reported in table 2. In particular, a significant higher prevalence of family history for early cardiovascular events ( $p$ $<0.04)$, retinopathy ( $\mathrm{p}<0.001)$ left ventricular hypertrophy $(\mathrm{p}<0.04)$ and carotid atherosclerosis $(\mathrm{p}<0.001)$ was found in hypertensives than normotensives. The genotype frequency distribution of the three polymorphisms was reported in table 3. Out of 194 subjects, the G894T, T786C and introne 4 genotypes were determined for 194 , 145 and 150 patients, respectively. Genotype frequency distribution is in accordance with the Hardy-Weinberg equilibrium and it is similar in the two groups. Only 4 aa genotype distribution was significantly $(\mathrm{p}<0.005)$ higher in hypertensives than normotensives.

T894, C786 and 4a were considered rare alleles and their relationship with study variables was analysed by dominant or recessive models, presenting only the former (GG versus $\mathrm{GT}+\mathrm{TT}$; TT versus $\mathrm{TC}+\mathrm{CC}$; bb versus $\mathrm{ab}+\mathrm{aa}$ ) because the results did not differ. Accordingly, in table 4 the relationship of cardiovascular damage and genotypes in hypertensives and normotensives was reported. The subgroup with cardiovascular damage was characterized by a greater prevalence $(\mathrm{p}<0.001)$ of $\mathrm{GT}+\mathrm{TT}, \mathrm{TC}+\mathrm{CC}$ genotype and homozygosis for the allele b (table 4). Moreover, to appraise the role of hypertension in the association among eNOS variants and cardiovascular damage, we compared the prevalence of eNOS genotype in the hypertensives and normotensives both with cardiovascular damage (table 5). Hypertensives with cardiovascular damage were characterized by a greater prevalence of G894T polymorphism $(\mathrm{p}<0.001)$ and introne 4 mutations $(\mathrm{p}<$ $0.05)$ than normotensives.

\section{Logistic regression}

We built a model of multiple logistic regression that included, among the independent variables, the presence or the absence of hypertension, BMI, age, sex and the heterozygous or homozygous genotypes The aim was to evaluate the possible association between the presence of cardiovascular damage and a determined eNOS genotype. From the analysis of the logistic regression, according to 
Table 5: Prevalence of eNOS genotype in hypertensives and normotensives with cardiovascular damage

\begin{tabular}{lcccc}
\hline G894T & Normotensives n.67 & $\%$ & Hypertensives n. I27 & $\%$ \\
\hline GG & 5 & 7.5 & 33 & $26.0^{*}$ \\
GT+TT & 14 & 20.9 & 52 & $40.9 \#$ \\
\hline
\end{tabular}

\begin{tabular}{lcccc}
\hline T786C & Normotensives n.38 & \% & Hypertensives n. 107 & $\%$ \\
\hline TT & 2 & 5.3 & 17 & 15.9 \\
TC+CC & 14 & 36.8 & 57 & 53.2 \\
\hline
\end{tabular}

\begin{tabular}{lcccc}
\hline Introne4 & Normotensives n. 31 & $\%$ & Hypertensives n. 119 & $\%$ \\
\hline $\mathrm{bb}$ & 10 & 32.3 & 62 & 52.1 \\
$\mathrm{ab}+\mathrm{aa}$ & 3 & 9.7 & 21 & $17.6 \S$ \\
\hline
\end{tabular}

$*_{\mathrm{p}}<0,001$ vs normotensives

$\# \mathrm{p}<0,007$ vs normotensives

$\S p<0,05$ vs normotensives

the model, only the age was associated to the presence of cardiovascular damage (OR 1.11; IC 95\% 1.06-1.18).

\section{Discussion}

Despite several clinical and experimental studies indicate a relevant role in the alteration of NO metabolism in the occurrence and severity of hypertension, no univocal date was reported on the influence of NO Synthase polymorphism and hypertension and its sequelae [5]. To our knowledge, this is the first study that has been designed to investigate the influence of G894T, T786C and intron4b/ a eNOS polymorphisms on cardiovascular damage in hypertensive subjects. It seems to indicate the following data:

-a) the distribution of the genotypes G894T and T786C is similar in hypertensives and normotensives, whereas the homozygous condition for the allele a of the introne 4 (4aa) is present in the $2.5 \%$ of the hypertensives, and it is completely absent in the normotensives;

-b) the subjects with cardiovascular damage were characterized by an increased prevalence of 4bb, 894 (GT+TT) and 786 (TC+CC) eNOS genotypes;

-c) a significant higher prevalence of G894T and introne 4 variants was found in hypertensives than normotensives with cardiovascular damage. In our opinion, this association doesn't reflect unknown differences in population ancestry between the case-control groups. We consider the probability of false positive inference attributable to population stratification rather small because the hyperten- sive and control subjects were recruited from an ethnically homogeneous population with no indication of a significant amount of a recent genetic admixture.

Although these data might suggest an association between eNOS polymorphisms and cardiovascular damage, logistic regression analysis indicates that only the age may be significantly associated with the cardiovascular damage in our population. Although few studies have so far addressed a similar issue, and all in clinical setting different from ours, this finding is consistent with results of the meta-analysis of Zintzaras et al [5] who point out that, despite there is an elevated genetic contribution in the control of arterial hypertension, complex mechanisms and other factors (e.g. age and smoking) interact one with another, and, in the long period, are likely to hide the real role of eventual genetic variations. In particular, a low statistical power might explain the low-entity association because our sample was empowered by its size to discriminate only allelic odds ratio not lower than 2. Moreover even though genetic linkage studies take advantage by focusing on relatively well-defined intermediate phenotypes (i.e. left ventricular hypertrophy, retinopathy, intima-media wall thickness etc....), the influence of multiple susceptibility genes with powerful environmental or gene-gene interactions makes it difficult to exclude confounding by some unmeasured factors [22,23]. Finally, the discrepancy by us observed among the possible presence of a greater prevalence of some genotypes in the hypertensives with cardiovascular damage in comparison to the normotensives and the results of the logistic regression emphasize some methodological biases in defining 
the role of genetic associations with a clinical condition, like cardiovascular damage, notoriously in progress and modifiable over the time. In our study this might be due to age of subjects we have recruited. Accordingly, to evaluate if this is the case, perspective studies including young hypertensive subjects and focusing on gene environment interactions as well as haplotype analysis are necessary.

\section{References}

I. Vallance P, Collier J, Moncada S: Effects of endothelium-derived nitric oxide on peripheral arteriolar tone in man. Lancet 1989, 2:997-1000.

2. Huang PL, Huang Z, Mashimo H, Bloch KD, Moskowitz MA, Bevan JA, Fishman MC: Hypertension in mice lacking the gene for endothelial nitric oxide synthase. Nature 1995, 377:239-242.

3. Haynes WG, Noon JP, Walker BR, Webb DJ: Inhibition of nitric oxide synthesis increases blood pressure in healthy humans. J Hypertens 1993, II: I375-1380.

4. Forte P, Copland M, Smith LM, Milne E, Sutherland J, Benjamin N: Basal nitric oxide synthesis in essential hypertension. Lancet 1997, 349:837-842.

5. Zintzaras E, Gergios K, Stefanidis I: Endotelial NO Synthase Gene Polymorphisms and Hypertension. Hypertension 2006, 48: I- I I.

6. Asakimori Y, Yorioka N, Tanaka J, Takasugi N, Harada S, Shigemoto K, Yamashita K, Usui K, Arita M, Kohno N: Association between ENOS gene polymorphism and cardiovascular events in nondiabetic hemodialysis patients: a prospective study. $\mathrm{Am} J$ Kidney Dis 2004, 44: I I 2-I 20.

7. Karvonen J, Kauma H, Kervinen $K$, Rantala M, Ikäheimo M, Päivänsalo M, Savolainen MJ, Kesäniemi YA: Endothelial nitric oxide synthase gene Glu298Asp polymorphism and blood pressure, left ventricular mass and carotid artery atherosclerosis in a population-based cohort. J Intern Med 2002, 25 I: 102-I I0.

8. Lacolley P, Gautier S, Poirier O, Pannier B, Cambien F, Benetos A: Nitric oxide synthase gene polymorphisms, blood pressure and aortic stiffness in normotensive and hypertensive subjects. J Hypertens 1998, 16:31-35.

9. Miyamoto $Y$, Saito $Y$, Kajiyama N, Yoshimura M, Shimasaki $Y$, Nakayama M, Kamitani S, Harada M, Ishikawa M, Kuwahara K, Ogawa E, Hamanaka I, Takahashi N, Kaneshige T, Teraoka H, Akamizu T, Azuma N, Yoshimasa Y, Yoshimasa T, Itoh H, Masuda I, Yasue H, Nakao K: Endothelial nitric oxide synthase gene is positively associated with essential hypertension. Hypertension 1998, 32:3-8.

10. Kato N, Sugiyama T, Morita H, Nabika T, Kurihara H, Yamori Y, Yazaki Y: Lack of evidence for association between the endothelial nitric oxide synthase gene and hypertension. Hypertension 1999, 33:933-936.

II. Benjafield AV, Morris B]: Association analyses of endothelial nitric oxide synthase gene polymorphisms in essential hypertension. Am J Hypertens 2000, I3:994-998.

12. Wang J, Dudley D, Wang XL: Haplotype-specific effects on endothelial NO synthase promoter efficiency: modifiable by cigarette smoking. Arterioscler Thromb Vasc Biol 2002, 22:el-4.

13. Tsujita Y, Baba S, Yamauchi R, Mannami T, Kinoshita M, Yamamoto R, Katsuya T, Higaki J, Ogihara T, Ogata J, Iwai N: Association analyses between genetic polymorphisms of endothelial nitric oxide synthase gene and hypertension in Japanese: The Suita Study. J Hypertens 2001, 19:1941-1948.

14. Shoji M, Tsutaya S, Saito R, Takamatu H, Yasujima M: Positive association of endothelial nitric oxide synthase gene polymorphism with hypertension in northern Japan. Life Sci 2000 66:2557-2562

15. Casa JP, Bautista LE, Humpries SE, Hingorani AD: Endothelial nitric oxide synthase genotype and ischemic heart disease. Metaanalysis of $\mathbf{2 6}$ studies involving $\mathbf{2 3 0 2 8}$ subjects. Circulation 2004, 109: 1359-1365.

16. Wattanapitayakul SK, Mihm MJ, Young AP, Bauer JA: Therapeutic implication of human endothelial nitric oxide Synthase gene polymorphism. Trends Pharmacol Sci 200I, 22:36I-368.

17. Crepaldi G, Belfiore F, Bosello O, Caviezel F, Contaldo F, Enzi G, Melchionda N: Special report: Italian Consensus ConferenceOverweight, Obesity and Health. Int J Obesity I99I, I 5:78|-790.
18. Licata G, Scaglione R, Corrao S, Ganguzza A, Mazzola G, Arnone S, Dichiara MA, Licata A, Merlino G, Di Chiara T: Heredity and obesity associated hypertension. Impact of hormonal characteristics and left ventricular mass. J Hypertens |995, |3:6 | I-6 |8.

19. De Simone G, Daniels SR, Devereux RB, Meyer RA, Roman MJ, de Divitiis $O$, Alderman $\mathrm{MH}$ : Left ventricular mass and body size in normotensive children an adults: assessment of allometric relations an impact of overweight. J Am Coll Cardiol 1992, 20: $125 \mid-1260$.

20. Armitage P, Berry G, Matthews JNS: Statistical Methods in Medical Research 4th edition. Oxford: Blackwell Science; 2002.

21. Hosmer DW, Lemeshow S: Applied Logistic Regression. New York: Wiley; 1989.

22. Dell'Omo G, Penno G, Pucci L, Fotino C, Lucchesi D, Del Prato S, Pedrinelli R: Lack of association between endothelial nitric oxide synthase gene polymorphisms, microalbuminuria and endothelial dysfunction in hypertensive men. J Hypertens 2007 , 25(7): I 389-95.

23. Pereira TV, Rudnicki M, Cheung BM, Baum L, Yamada Y, Oliveira PS, Pereira AC, Krieger JE: Three endothelial nitric oxide (NOS3) gene polymorphisms in hypertensive and normotensive individuals: meta-analysis of $\mathbf{5 3}$ studies reveals evidence of publication bias. J Hypertens 2007, 25(9): I 763-74.
Publish with Bio Med Central and every scientist can read your work free of charge

"BioMed Central will be the most significant development for disseminating the results of biomedical research in our lifetime. "

Sir Paul Nurse, Cancer Research UK

Your research papers will be:

- available free of charge to the entire biomedical community

- peer reviewed and published immediately upon acceptance

- cited in PubMed and archived on PubMed Central

- yours - you keep the copyright
BioMedcentral 